\title{
Seed collection strategies for plant restoration with the aid of neutral genetic diversity
}

\author{
Mi Yoon CHUNG, Sungwon SON ${ }^{1}$, Kangshan $\mathrm{MAO}^{2}$, \\ Jordi LÓPEZ-PUJOL ${ }^{3}$ and Myong Gi CHUNG ${ }^{4 *}$ \\ Division of Life Science and the Research Institute of Natural Science (RINS), Gyeongsang National University, Jinju 52828, Korea \\ ${ }^{1}$ Division of Plant Resources, Korea National Arboretum, Yangpyeong 12519, Korea \\ ${ }^{2}$ Key Laboratory for Bio-resources and Eco-environment of Ministry of Education, College of Life Science, \\ State Key Laboratory of Hydraulics and Mountain River Engineering, Sichuan University, Chengdu 610065, China \\ ${ }^{3}$ Botanic Institute of Barcelona (IBB, CSIC-ICUB), Barcelona 08038, Catalonia, Spain \\ ${ }^{4}$ Department of Biology and RINS, Gyeongsang National University, Jinju 52828, Korea \\ (Received 29 October 2019; Revised 12 December 2019; Accepted 16 December 2019)
}

\begin{abstract}
One key step in the plant restoration process is the collection of seeds from the field. For the selection of source populations of target plant species for translocation purposes (reintroduction or reinforcements), several approaches are possible. A practical method involves the use of data from reciprocal transplant studies. If no direct data are available, knowledge of population genetics and the phylogeography of the target species can serve as an alternative. In this short review, we briefly propose guidelines for those collecting seeds for plant species restoration based on population genetics theory, focusing on two main questions: Where does the plant material come from and how are sources designated, and how are seeds efficiently collected from local populations? While genetic data on a larger scale (phylogeography and population genetics) are needed to form a reply to the first question, similar data on a smaller scale (fine-scale genetic structures within populations) are necessary to shed light on the second issue.
\end{abstract}

Keywords: conservation, genetic diversity, neutral variation, quantitative traits

Evolutionary factors such as random genetic drift and gene flow are detected and quantified by a spectrum of formulae and models based on neutral genetic markers. If these forces affect all genes in a similar fashion, one would expect comparable effects on adaptive genetic variation as well. Similarly, populations with low levels of neutral genetic diversity would be less able to adapt to novel selection pressures, because a limited gene pool would reduce the likelihood of adaptive alleles being present in a population (Pujol and Pannell, 2008; Markert et al., 2010; Kirk and Freeland, 2011). In reality, however, poor correlations between overall neutral heterozygosity and fitness-related traits may be in part due to the fact that several or dozens of neutral marker loci actually represent a very small part of the genome; indeed, some empirical studies have shown that variability at neutral markers (e.g., simple sequence repeats [SSRs]) may not accurately reflect the underlying genomic diversity (Väli et al., 2008). Although neutral genetic variation is not always a "surrogate" of the amount of resilience of a population in response to stressors such as drought or diseases, it is important to note its application to infer a variety of ecological and evolutionary processes, including mating systems (selfing vs. outcrossing), inbreeding, effective population sizes, demographic events, gene flow, historical patterns of dispersal, spatial genetic structure within populations or parentage. All these have important conservation or restoration implications.

Reintroduction has become increasingly important in conservation worldwide for the recovery of rare species and restoration purposes (Maunder, 1992; Godefroid and Vanderborght, 2011; Godefroid et al., 2011; Abeli and Dixon, 2016; Volis, 2016; Maschinski and Albrecht, 2017). According to the last version of IUCN's Guidelines for Reintroductions

\footnotetext{
*Author for correspondence: mgchung@gnu.ac.kr
} 
and Other Conservation Translocations (IUCN/SSC, 2013), reintroduction is a general term that describes the intentional placement of plant material into a natural or managed ecological area. It also has a stricter definition, i.e., the release and management of a plant into an area in which it formerly occurred, but in which it is now extinct or believed to be extinct (also called reinstatement or re-establishment). Introduction is also defined as a release of a plant but outside its indigenous range. Reinforcement is an effort to increase population size or diversity by adding individuals to an existing population of conspecifics (also called augmentation, supplementation, restocking or enhancement). Translocation is the transfer (direct transportation or transplantation) of material from one part to another, either inside or outside indigenous range of a species and, thus, includes both reintroduction and introduction but also reinforcement activities. Within the guidelines, population restoration is defined as any translocation to within indigenous range, thus comprising both reintroductions and reinforcements. However, as the adaptive capacity of the focal species will tend to be higher in populations with high adaptive genetic diversity (IUCN/SSC, 2013), for reintroductions and other translocation activities (reinforcements and introductions), it is of importance to identify populations harboring high levels of diversity. The writers of these guidelines do mention "genetic diversity" in several places in the document and, in our opinion, it is not clear whether they are assuming that levels of neutral genetic diversity are indicative of those of adaptive genetic diversity.

The importance of considering (neutral and adaptive) genetic variation in the conservation of rare plants is generally acknowledged (Falk and Holsinger, 1991; Hamrick and Godt, 1996; Rieseberg and Swensen, 1996). In addition, the importance of considering genetic diversity in plant restoration is often discussed (Fenster and Dudash, 1994; Mistretta, 1994; Havens, 1998; Falk et al., 2001, 2006; Hufford and Mazer, 2003; Volis, 2016). As a result, various guidelines or suggestions have been proposed for the collection of propagules (mostly seeds) for plant restoration based on population genetics theory (Knapp and Rice, 1994; Center for Plant Conservation, 1996; McKay et al., 2005; Vander Mijnsbrugge et al., 2010). As of 2011, however, there were only 20 plant species $(8 \%)$ with some knowledge of genetic variation out of 249 plant species reintroductions conducted worldwide (Godefroid et al., 2011). Despite that mean survival rates of reintroduced native species are quite low (on average $52 \%, 19 \%$, and $16 \%$ for survival, flowering, and fruiting, respectively), these increase significantly when there is genetic information available (Godefroid et al., 2011). Thus, although it may be difficult to exactly know how practitioners have used genetic information for their conservation implementationbecause many data are currently unpublished or in reports with restricted access, knowledge of the adaptive (if not available, neutral) genetic variation of target species is an important asset that positively influences plant reintroduction outcomes (Godefroid et al., 2011).

In this short review, we tentatively follow the assumption that neutral genetic diversity is a "surrogate" of adaptive genetic diversity and, then, using neutral genetic information, we suggest strategies of seed collection for species of conservation concern, both at larger scales (from genetic information across the geographic range, e.g., phylogeography) and at smaller scales (from fine-scale genetic structure [FSGS; the nonrandom spatial distribution of individual genotypes]) in their local populations.

\section{Where Does Plant Material Come from and How Sources Are Designated?}

There are excellent reviews about general ecological guidelines or approaches on plant conservation (Maschinski and Albrecht, 2017; Center for Plant Conservation, 2019), the genetics of restoration (Mistretta, 1994; McKay et al., 2005; Falk et al., 2006), and seed collection strategies (Vander Mijnsbrugge et al., 2010). However, these studies do not focus on how to choose seed sources and how to collect them with the aid of (neutral) genetic information.

Among the genetic diversity parameters, $F_{\mathrm{ST}}$ (or $G_{\mathrm{ST} ;}$ a measure of among-population genetic differentiation) is important for deciding how many populations have to be conserved and which populations are candidates to be the source of restored populations. The key points of the " $F_{\mathrm{ST}}$ " based conservation genetics paradigm" are the following: (1) for species with "little" interpopulation divergence, fewer populations are needed to be sampled for ex situ conservation, or protected in situ; (2) in contrast, species with "high" interpopulation divergence require more extensive population sampling for ex situ conservation, or the conservation of more populations in situ; and (3) in addition, conservation managers and practitioners should collect seeds or propagules from populations that have low pairwise $F_{\mathrm{ST}}$ values with the population(s) to be restored. The adjectives "little" (or "low") or "high" based solely on $F_{\mathrm{ST}}$ values could be subjective when restoration managers or practitioners apply this information to the formulation of a seed-collection policy. Any such classification scheme would be somewhat artificial since $F_{\text {ST }}$ ranges on a continuum from close to 0.00 to about 0.70 based 
on allozyme data (J. L. Hamrick, pers. comm.). Thus, thresholds for rating $F_{\mathrm{ST}}$ as "low" or "high" can differ from one researcher to another: e.g., Wright (1951) suggests that $F_{\mathrm{ST}}$ values of 0.00-0.05 represent "little" genetic differentiation and values $>0.15$ represent "great" genetic differentiation; J. L. Hamrick (pers. comm.) considers $F_{\mathrm{ST}}<0.10$ as "low" and values $>0.40$ as "high". Thus, researchers should justify their decision on classifying $F_{\mathrm{ST}}$ as "little" (or "low") or "high."

To reduce potential risks of outbreeding depression, it is important to identify "seed zones" (Vander Mijnsbrugge et al., 2010), which represent areas in which historical and contemporary gene flow occur; therefore, it is expected that within the zones transfer of plant material would have no negative impact. One approach to delineate seed zones is to test seeds of different origin in common garden experiments resulting in species-specific models, which relate genetic variation to geographic and/or climatic variation (e.g., Campbell, 1991; Rehfeldt, 1995; Lindgren and Ying, 2000). Through classical reciprocal transplant experiments it is possible to determine whether plant species under conservation concern are locally adapted at a regional scale and whether they are locally differentiated between neighboring populations (Waser and Price, 1985; Rice and Mack, 1991; Leiss and MüllerSchärer, 2001; Bischoff et al., 2006 and references therein). However, such kind of large-scale studies (reciprocal transplant experiments) and common garden studies are too time- and resources-consuming for most researchers (Becker et al., 2006; Bischoff et al. 2006). Furthermore, for many species such data are lacking and the distance over which gene flow takes place is unknown. A simplified approach is the delineation of seed zones using environmental criteria such as geographical distance, climate and geomorphology, and administrative divisions by latitude, longitude, and altitude (Ying and Yanchuk, 2006; Vander Mijnsbrugge et al., 2010). However, the borders of environmentally based seed zones are often arbitrary and it is unlikely that they reflect the real $F_{\mathrm{ST}}$ of a plant species.

Molecular markers such as allozymes, inter simple sequence repeats, amplified fragment length polymorphisms, and microsatellites or SSRs, chloroplast DNA (cpDNA), or mitochondrial DNA, alone or in combination, provide a relatively powerful tool that may help to delineate evolutionary significant units and/or phylogeographic groups, which provide the basis for designing "seed zones" (e.g., Vander Mijnsbrugge et al., 2003; Krauss and Koch, 2004; Krauss and He, 2006; Hubert and Cottrell 2007; Chung et al., unpubl. data). For example, Zeng et al. (2015) examined the genetic diversity and structure of 29 populations of the Mongolian oak Quercus mongolica (SSRs, $F_{\mathrm{ST}}=0.020$ and $H_{\mathrm{eP}}$ Hardy-Weinberg expected heterozygosity within populations $=0.746$, thus belonging to "the low $G_{\mathrm{ST}}$ and high $H_{\mathrm{eP}}$ " scenario) (Ottewell et al., 2016) within its natural range in northeastern China and the Korean Peninsula (except North Korea) using multiple approaches (19 nuclear SSR [nSSR] loci and four cpDNA fragments). Analysis of cpDNA variation revealed four lineages that were largely but incompletely geographically disjunct. However, Bayesian clustering analysis with nSSRs revealed five groups with a strong geographical basis: the Korean Peninsula group; the Changbai Mts. group that consisted mostly of populations from these mountains plus two western populations; the "MR" group that consisted of a single population (MR) in northeast China; the Xiaoxing'an Mts. group that consisted of populations from these mountains plus the only population in the Daxing'an Mts.; and the Russian Far East group. These five regions have been considered as glacial refugia for $Q$. mongolica during the Last Glacial Maximum and, accordingly, they might be roughly delineated as seed zones.

A somewhat contrasting scenario is found in the woody shrub Yunnan peony (Paeonia delavayi), which belongs to "the high $G_{\mathrm{ST}}$ and low $H_{\mathrm{eP}}$ " scenario (Ottewell et al., 2016) (SSRs, $F_{\mathrm{ST}}=0.510$ and $H_{\mathrm{eP}}=0.369$ ). Zhang et al. (2018) used nuclear SSRs, cpDNA, and ecological niche modeling in 13 populations to gain insights into its past evolutionary history and found that $P$. delavayi survived in either (1) macrorefugia that would have existed around the current ranges for southernmost populations, or in (2) microrefugia for the northernmost populations of Sichuan, or (3) retreated towards warmer places in southwestern China; so, a dual model seems to apply for $P$. delavayi (in situ persistence and retreat to refugia). As the high $F_{\mathrm{ST}}$ reflected, Bayesian clustering analysis with nSSRs revealed approximately 11 genetic groups out of 13 populations: except the three populations that are supposed to have retreated into refugia in SW China and that are clustered into a single group (BOM1, BOM2, and NYI), the remaining 10 populations approximately correspond with 10 groups. These might represent distinct seed zones, and for ex situ restoration seeds could be collected from all these populations. Similar strategy should be considered for other plant species that occur in topographic complex regions in the light of the findings based on neutral molecular markers.

\section{How Are Seeds Efficiently Collected in Local Populations?}

A commonly used approach in population genetics is FSGS, that has been used to detect family structure in local populations (Chung and Epperson, 1999; Diniz-Filho and Telles, 2002; 
Escudero et al., 2003; Torres et al., 2003; Van Rossum and Triest, 2006). Family structure can result solely from limited seed dispersal, which may lead to genetically distinct seed shadows among maternal plants (e.g., Perry and Knowles, 1991; Berg and Hamrick, 1995; Chung et al., 2003). Moreover, if pollen dispersal is also restricted, this could eventually cause the buildup of more intense genetic structure within populations over many generations (Linhart et al., 1981; Hamrick and Nason, 1996). In contrast, if seeds are widely and independently dispersed, only a weak spatial genetic structure will result (e.g., Dewey and Heywood, 1988; Loiselle et al., 1995; Chung and Epperson, 2000; Chung et al., 2000a, 2000b).

Spatial statistical methods provide powerful tools for measuring the structure of genetic diversity within populations of target species for plant conservation biologists (Escudero et al., 2003). Analysis of FSGS within plant populations of threatened or narrowly distributed species could be used to provide baseline information for sampling strategies for ex situ preservation of seeds in gene banks and for selecting the sites and population sizes necessary for in situ conservation (Maki and Yahara, 1997; Diniz-Filho and Telles, 2002; Escudero et al., 2003; Chung et al., 2004). Moran's correlogram is one of the approaches to illustrate FSGS, where the first $x$-axis intercept of the correlogram is considered to approximate the "patch size" (the spatial scale within which individuals have similar genetic background) or the extent of nonrandom genetic structure (Sokal, 1979). The genetic patch width thus reflects the clustering of genetically related individuals as well as the distance at which the majority of seeds are dispersed (Sokal and Wartenberg, 1983). It should be noted that Fenster et al. (2003) have shown that estimating the distance at which the correlogram (based on pairwise kinship coefficients) first intercepts the abscissa is sensitive to sampling scheme, calling into question the utility of comparisons made across species or across studies. Many rare species, however, are highly isolated in a scale of tens or hundreds of kilometers. If populations of rare species are sampled at the same (or similar) scales, then the "patch size" can be compared reasonably. If there is strong FSGS, then sampling should be conducted at a scale larger than the patch size to optimize sampling design by avoiding "pseudoreplication". Since many trees with high dispersal potential (e.g., oaks and pines) often exhibit a weak FSGS (Berg and Hamrick, 1995; Epperson and Chung, 2001), this approach would be more efficient as a sampling tool for rare herbaceous plants than for common tree species (Chung et al., 1999).

Chung et al. (1999) used allozyme loci, join-count statistics, and Moran's spatial autocorrelation statistics to separate the
FSGS caused by clonal reproduction from that maintained in sexually reproducing individuals in a highly isolated population (a $20 \times 20$-m area) of the insect-pollinated, rare perennial herb Lycoris sanguinea var. koreana in southern Korea. Join-count statistics showed a significant clustering of clonal genotypes at short distances $(2 \mathrm{~m})$. The authors found that the population is structured on a small scale with an approximate genetic patch width of $6 \mathrm{~m}$, largely due to restricted seed and pollen dispersal. To efficiently extract the genetic diversity, the authors suggested that sampling methods for seed stocks or bulbs could be optimized by collecting at $6-\mathrm{m}$ intervals across the local population. Another example of conservation-oriented FSGS study was carried out with the insect-pollinated, endangered perennial herb Hanabusaya asiatica in central Korea. Chung et al. (2001) used allozyme loci and Moran's spatial autocorrelation statistics to estimate patch size in two local populations $(35 \times$ $60 \mathrm{~m}$ and $40 \times 80 \mathrm{~m}$ ). The authors found that the genetic patch width in the examined populations of $H$. asiatica was approximately 5-8 m. For conservation purposes, the authors suggested that, in general, the sampling of $H$. asiatica should be conducted at 5-8 m intervals in order to efficiently sample the genetic diversity across an entire population.

\section{Final Remarks and Conclusions}

As neutral markers would be poor "surrogates" for adaptive variation, delimitation of seed zones should also take into account habitat differences within them. In addition, we suggest to conduct FSGS separately according to habitat differences (e.g., dry vs. wet; south-facing vs. north-facing) to prevent mixing different ecotypes. If there are distinct habitat differences within seed zones, sampling within locally adapted populations is more appropriate (that is, each seed zone could be further divided into local populations), because local populations often show a home-site advantage and the introduction of non-local genotypes may have negative consequences (McKay et al., 2005; Volis, 2011; but see Bischoff et al., 2006). However, conservation practitioners should be aware that populations further away but from similar habitats may be better adapted than neighboring populations showing a fairly distinct habitat (Vander Mijnsbrugge et al., 2010).

Designing seed zones may also vary depending on the lifehistory traits. In general, as trees maintain significantly higher within-population genetic diversity and lower amongpopulation differentiation compared to herbaceous perennials and annuals, criteria for designing seed zones should be different between trees and herbs; as a general rule, thus, seeds of herbaceous plants would be collected at a much more local 
scale than woody plants (Chung et al., unpubl. data). In cases of no genetic information (e.g., when phylogeographic or FSGS studies have not been carried out), it would be wise to follow "a general rule" or "a somewhat modified plan of sampling strategy": according to the Center for Plant Conservation (2019), collections of about 3,000 seeds from 50 unrelated maternal plants within a population would be enough.

To conclude, in this review we showed that phylogeographic and population genetic information could be useful for the accurate identification of "seed zones," while "patch sizes" can be estimated from moderate or strong FSGS in highly isolated populations of rare plant species (especially for herbaceous perennials and annuals). Both approaches can be used to design sampling strategies (e.g., seed sampling should be at a scale larger than the patch size in each local population) for rare and threatened plant species.

ORCID: Mi Yoon CHUNG https://orcid.org/0000-0002-87565367; Kangshan MAO https://orcid.org/0000-0002-0071-1844; Jordi LÓPEZ-PUJOL https://orcid.org/0000-0002-2091-6222; Myong Gi CHUNG https://orcid.org/0000-0002-1283-3574

\section{Acknowledgments}

The corresponding author (MGC) thanks Prof. James L. Hamrick and John Nason who have kindly responded to questions related to the preparation of this review. We thank Pankaj Kumar for editing the earlier version of the manuscript. This research was supported by the Basic Science Research Program through the National Research Foundation of Korea (NRF) funded by the Ministry of Education (NRF2013R1A1A3010892 to M.Y.C. and NRF-2013R1A1A2063524 and NRF-2017R1A2B4012215 to M.G.C.) and was carried out as part of the Infrastructure for the Conservation and Restoration of Rare and Endemic Plants in Korea National Arboretum that supported to MGC from 2015 to 2019. KM was supported by National Natural Science Foundation of China (grant no. 31622015).

\section{Conflict of Interest}

The authors declare that there are no conflicts of interest.

\section{Literature Cited}

Abeli, T. and K. Dixon. 2016. Translocation ecology: the role of ecological sciences in plant translocation. Plant Ecology 217: $123-125$.
Becker, U., T. Reinhold and D. Matthies. 2006. Effects of pollination distance on reproduction and offspring performance in Hypochoeris radicata: experiments with plants from three European regions. Biological Conservation 132: 109-118.

Berg, E. E. and J. L. Hamrick. 1995. Fine-scale genetic structure of a Turkey oak forest. Evolution 49: 110-120.

Bischoff, A., L. Crémieux, M. Smilauerova, C. S. Lawson, S. R. Mortimer, J. Dolezal, V. Lanta, A. R. Edwards, A. J. Brook, M. Macel, J. Leps, T. Steinger and H. Müller-Schärer. 2006. Detecting local adaptation in widespread grassland species: the importance of scale and local plant community. Journal of Ecology 94: 1130-1142.

Campbell, R. K. 1991. Soils, seed-zone maps, and physiography: guidelines for seed transfer of Douglas-fir in south-western Oregon. Forest Science 37: 973-986.

Center for Plant Conservation. 1996. Guidelines for developing a rare plant reintroduction plan. In Restoring Diversity. Falk, D. A., C. I. Millar and M. Olwell (eds.), Island Press, Washington, DC. Pp. 453-490.

Center for Plant Conservation. 2019. The importance of representing genetic diversity in plant conservation collections. CPC Best Plant Conservation Practices to Support Species Survival in the Wild. Retrieved Sep. 21, 2019, available from: https:// plantnucleus.com/best-practices/importance-representinggenetic-diversity-plant-conservation-collections.

Chung, M. G. and B. K. Epperson. 1999. Spatial genetic structure of clonal and sexual reproduction in populations of Adenophora grandiflora (Campanulaceae). Evolution 53: 10681078.

Chung, M. G. and B. K. Epperson. 2000. Spatial genetic structure of allozyme polymorphisms in a population of Eurya japonica (Theaceae). Silvae Genetica 49: 1-4.

Chung, M. G., J. M. Chung, M. Y. Chung and B. K. Epperson. 2000a. Spatial distribution of allozyme polymorphisms following clonal and sexual reproduction in populations of Rhus javanica (Anacardiaceae). Heredity 84: 178-185.

Chung, M. G., M. Y. Chung, G. S. Oh and B. K. Epperson. 2000 b. Spatial genetic structure in a Neolitsea sericea population (Lauraceae). Heredity 85: 490-497.

Chung, M. G., M. Y. Chung and B. K. Epperson. 2001. Conservation genetics of an endangered herb, Hanabusaya asiatica (Campanulaceae). Plant Biology 3: 42-49.

Chung, M. Y., B. K. Epperson and M. G. Chung. 2003. Genetic structure of age classes in Camellia japonica (Theaceae). Evolution 57: 62-73.

Chung, M. Y., C. P. Chun and M. G. Chung. 1999. Clonal and spatial genetic structure in a population of the endangered herb Lycoris sanguinea var. koreana (Amaryllidaceae). Genes and 
Genetic Systems 74: 61-66.

Chung, M. Y., J. D. Nason and M. G. Chung. 2004. Spatial genetic structure in populations of the terrestrial orchid Cephalanthera longibracteata (Orchidaceae). American Journal of Botany 91: 52-57.

Dewey, S. E. and J. S. Heywood. 1988. Spatial genetic structure in a population of Psychotria nervosa. I. Distribution of genotypes. Evolution 42: 834-838.

Diniz-Filho, J. A. F. and M. P. C. Telles. 2002. Spatial autocorrelation analysis and the identification of operational units for conservation in continuous populations. Conservation Biology 16: $924-935$.

Epperson, B. K. and Chung, M. G. 2001. Spatial genetic structure of allozyme polymorphisms within populations of Pinus strobus (Pinaceae). American Journal of Botany 88: 1006-1010.

Escudero, A., J. M. Iriondo and M. E. Torres. 2003. Spatial analysis of genetic diversity as a tool for plant conservation. Biological Conservation 113: 351-365.

Falk, D. A. and K. E. Holsinger. 1991. Genetics and Conservation of Rare Plants. Oxford University Press, New York, NY, 304 pp.

Falk, D. A., E. E. Knapp and E. O. Guerrant. 2001. An Introduction to Restoration Genetics. Plant Conservation Alliance, Bureau of Land Management, US Department of Interior, US Environmental Protection Authority. Retrieved Sep. 21, 2019, available from: http://www.ser.org/pdf/SER -restoration-genetics.pdf.

Falk, D. A., C. M. Richards, A. M. Montalvo and E. E. Knapp. 2006. Population and ecological genetics in restoration ecology. In Foundations of Restoration Ecology. Falk, D. A., M. A. Palmer and J. B. Zedler (eds.), Island Press, Washington, DC. Pp. 14-41.

Fenster, C. B. and M. R. Dudash. 1994. Genetic considerations for plant population restoration and conservation. In Restoration of Endangered Species. Bowles, M. L. and C. J. Whelan (eds.), Cambridge University Press, Cambridge. Pp. 34-62.

Fenster, C. B., X. Vekemans and O. J. Hardy. 2003. Quantifying gene flow from spatial genetic structure data in a metapopulation of Chamaecrista fasciculata (Leguminosae). Evolution 57: 995-1007.

Godefroid, S., C. Piazza, G. Rossi, S. Buord, A.-D. Stevens, R. Aguraiuja, C. Cowell, C. W. Weekley, G. Vogg, J. M. Iriondo, I. Johnson, B. Dixon, D. Gordon, S. Magnanon, B. Valentin, K. Bjureke, R. Koopman, M. Vicens, M. Virevaire and T. Vanderborght. 2011. How successful are plant species reintroductions? Biological Conservation 144: 672-682.

Godefroid, S. and T. Vanderborght. 2011. Plant reintroductions: the need for a global database. Biodiversity and Conservation
20: $3683-3688$.

Hamrick, J. L. and M. J. W. Godt. 1996. Conservation genetics of endemic plant species. In Conservation Genetics: Case Histories from Nature. Avise, J. C. and J. L. Hamrick (eds.), Chapman \& Hall, New York, NY. Pp. 281-304.

Hamrick, J. L. and J. D. Nason. 1996. Consequences of dispersal in plants. In Population Dynamics in Ecological Space and Time. Rhodes, O. E. Jr., R. K. Chesser and M. H. Smith (eds.), University of Chicago Press, Chicago, IL. Pp. 203-236.

Havens, K. 1998. The genetics of plant restoration. Restoration and Management Notes 16: 68-72.

Hubert, J. and J. Cottrell. 2007. The Role of Forest Genetic Resources in Helping British Forests Respond to Climate Change. Forestry Commission, Edinburgh, 12 pp.

Hufford, K. M. and S. J. Mazer. 2003. Plant ecotypes: genetic differentiation in the age of ecological restoration. Trends in Ecology and Evolution 18: 147-155.

IUCN/SSC. 2013. Guidelines for Reintroductions and Other Conservation Translocations. Version 1.0. IUCN Species Survival Commission, Gland, 57 pp.

Kirk, H. and J. R. Freeland. 2011. Applications and implications of neutral versus non-neutral markers in molecular ecology. International Journal of Molecular Sciences 12: 3966-3988.

Knapp, E. E. and K. J. Rice. 1994. Starting from seed: Genetic issues in using native grasses for restoration. Restoration and Management Notes 12: 40-45.

Krauss, S. L. and J. M. Koch. 2004. Rapid genetic delineation of provenance for plant community restoration. Journal of Applied Ecology 41: 1162-1173.

Krauss, S. L. and T. H. He. 2006. Rapid genetic identification of local provenance seed collection zones for ecological restoration and biodiversity conservation. Journal for Nature Conservation 14: 190-199.

Leiss, K. A. and H. Müller-Schärer. 2001. Adaptation of Senecio vulgaris (Asteraceae) to ruderal and agricultural habitats. American Journal of Botany 88: 1593-1599.

Lindgren, D. and C. C. Ying. 2000. A model integrating source adaptation and seed use. New Forests 20: 87-104.

Linhart, Y. B., J. B. Mitton, K. B. Sturgeon and M. L. Davis. 1981. Genetic variation in space and time in a population of ponderosa pine. Heredity 46: 407-426.

Loiselle, B. A., V. L. Sork, J. Nason and C. Graham. 1995. Spatial genetic structure of a tropical understory shrub, Psychotria officinalis (Rubiaceae). American Journal of Botany 82: 1420-1425.

Maki, M. and T. Yahara. 1997. Spatial structure of genetic variation in a population of the endangered plant Cerastium fischerianum var. molle (Caryophyllaceae). Genes and Genetics 
Systems 72: 239-242.

Markert, J. A., D. M. Champlin, R. Gutjahr-Gobell, J. S. Grear, A. Kuhn, T. J. McGreevy, A. Roth, M. J. Bagley and D. E. Nacci. 2010. Population genetic diversity and fitness in multiple environments. BMC Evolutionary Biology 10: 205.

Maschinski, J. and M. A. Albrecht. 2017. Center for Plant Conservation's Best Practice Guidelines for the reintroduction of rare plants. Plant Diversity 39: 390-395.

Maunder, M. 1992. Plant reintroduction: an overview. Biodiversity and Conservation 1: 51-61.

McKay, J. K., C. E. Christian, S. Harrison and K. J. Rice. 2005. "How local is local?": a review of practical and conceptual issues in the genetics of restoration. Restoration Ecology 13: 432-440.

Mistretta, O. 1994. Genetics of species re-introductions: applications of genetic analysis. Biodiversity and Conservation 3: 184-190.

Ottewell, K. M., D. C. Bickerton, M. Byrne and A. J. Lowe. 2016. Bridging the gap: a genetic assessment framework for population-level threatened plant conservation prioritization and decision-making. Diversity and Distributions 22: 174-188.

Perry, D. J. and P. Knowles. 1991. Spatial genetic structure within three sugar maple (Acer saccharum Marsh.) stands. Heredity 66: 137-142.

Pujol, B. and J. R. Pannell. 2008. Reduced responses to selection after species range expansion. Science 321: 96.

Rehfeldt, G. E. 1995. Genetic variation, climate models and the ecological genetics of Larix occidentalis. Forest Ecology and Management 78: 21-37.

Rice, K. J. and R. N. Mack. 1991. Ecological genetics of Bromus tectorum. III. The demography of reciprocally sown populations. Oecologia 88: 91-101.

Rieseberg, L. H. and S. M. Swensen. 1996. Conservation genetics of endangered island plants. In Conservation Genetics: Case Histories from Nature. Avise, J. C. and J. L. Hamrick (eds.), Chapman \& Hall, New York, NY. Pp. 305-334.

Sokal, R. R. 1979. Ecological parameters inferred from spatial correlograms. In Contemporary Quantitative Ecology and Related Ecometrics. Patil, G. P. and M. L. Rosenzweig (eds.), International Cooperative Publishing House, Fairland, MD. Pp. 167196.

Sokal, R. R. and D. E. Wartenberg. 1983. A test of spatial autocorrelation analysis using an isolation-by-distance model.
Genetics 105: 219-237.

Torres, E., J. M. Iriondo, A. Escudero and C. Pérez. 2003. Analysis of within-population spatial genetic structure in Antirrhinum microphyllum (Scrophulariaceae). American Journal of Botany 90: 1688-1695.

Väli, U., A. Einarsson, L. Waits and H. Ellegren. 2008. To what extent do microsatellite markers reflect genome-wide genetic diversity in natural populations? Molecular Ecology 17: 38083817.

Van Rossum, F. and L. Triest. 2006. Fine-scale genetic structure of the common Primula elatior (Primulaceae) at an early stage of population fragmentation. American Journal of Botany 93: 1281-1288.

Vander Mijnsbrugge, K., A. Bischoff and B. Smith. 2010. A question of origin: where and how to collect seed for ecological restoration. Basic and Applied Ecology 11: 300-311.

Vander Mijnsbrugge, K., E. Coart, H. Beeckman and J. Van Slycken. 2003. Conservation measures for autochthonous oaks in Flanders. Forest Genetics 10: 207-217.

Volis, S. 2011. Adaptive genetic differentiation in a predominantly self-pollinating species analyzed by transplanting into natural environment, crossbreeding and $Q_{\mathrm{ST}}-F_{\mathrm{ST}}$ test. New Phytologist 192: 237-248.

Volis, S. 2016. Conservation-oriented restoration: how to make it a success? Israel Journal of Plant Sciences 63: 276-296.

Waser, N. M. and M. V. Price. 1985. Reciprocal transplant experiments with Delphinium nelsonii (Ranunculaceae): evidence for local adaptation. American Journal of Botany 72: 17261732.

Wright, S. 1951. The genetical structure of populations. Annals of Eugenics 15: 323-354.

Ying, C. C. and A. D. Yanchuk. 2006. The development of British Columbia's tree seed transfer guidelines: purpose, concept, methodology, and implementation. Forest Ecology and Management 227: 1-13.

Zeng, Y.-F., W.-T. Wang, W.-J. Liao, H.-F. Wang and D.-Y. Zhang. 2015. Multiple glacial refugia for cool-temperate deciduous trees in northern East Asia: the Mongolian oak as a case study. Molecular Ecology 24: 5676-5691.

Zhang, Z.-M., J. López-Pujol, X. Gong, H.-F. Wang, R. Vilatersana and S.-L. Zhou. 2018. Population genetic dynamics of Himalayan-Hengduan tree peonies, Paeonia subsect. Delavayanae. Molecular Phylogenetics and Evolution 125: 62-77. 